\title{
Mycophenolate mofetil in patients with refractory systemic autoimmune myopathies: case series
}

\author{
Pablo Arturo Olivo Pallo, Fernando Henrique Carlos de Souza, Renata Miossi and Samuel Katsuyuki Shinjo
}

\begin{abstract}
Background: Currently, there are only few studies (mostly case reports or case series) on mycophenolate mofetil (MMF) in patients with systemic autoimmune myopathies (SAM). Therefore, the goal of the present study was to evaluate the safety and efficacy of MMF (monotherapy or coadjuvant drug) in a specific sample of patients with refractory SAM: dermatomyositis, polymyositis, anti-synthetase syndrome or clinically amyopathic dermatomyositis.

Methods: A case series including 20 consecutive adult patients with refractory SAM from 2010 to 2016 was conducted. After the introduction of MMF, associated or not with other drugs, the patients were followed for 6 consecutive months.

Results: In 17 out of 20 patients MMF was introduced without any intolerance. The clinical symptoms evaluated in these patients were muscular, cutaneous and/or pulmonary activity. During the 6-month follow-up, 11 out of 17 patients had clinical and laboratory activities response with MMF, allowing significant tapering of the prednisone median dose (15 vs. $5 \mathrm{mg} / \mathrm{day}, P=0.005$ ). On the other hand, in three out of 20 patients; MMF was discontinued in less than two months, because of gastrointestinal intolerance. There were no cases of serious infection or death.

Conclusions: MMF was relatively well-tolerated, safe and effective in patients with refractory SAM. Further studies are needed to confirm the data found.
\end{abstract}

Keywords: Dermatomyositis, Drugs, Immunomodulator, Immunosuppressive, Myositis, Polymyositis

\section{Background}

Systemic autoimmune myopathies (SAM) are a heterogeneous group of rare systemic autoimmune diseases that result in progressive skeletal muscle weakness and disability [1-3]. Depending on the demographic, clinical, laboratory, histological and disease evaluation, SAM can be classified into dermatomyositis (DM), polymyositis (PM), inclusion body myositis, or immune-mediated necrotizing myopathy, among others [2-4].

There are no randomized controlled clinical trials and glucocorticoid has been used as the first-line drug in SAM $[5,6]$. Various immunosuppressive or immunomodulatory drugs have been recommended as glucocorticoid-sparing agents, including methotrexate, azathioprine, cyclosporine,

\footnotetext{
*Correspondence: samuel.shinjo@gmail.com

Division of Rheumatology, Faculdade de Medicina FMUSP, Universidade de Sao Paulo, Av. Dr. Arnaldo, 455, 3 andar, sala 3150 - Cerqueira César, CEP 01246-903 Sao Paulo, Brazil
}

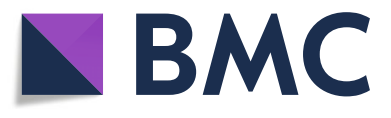

(c) The Author(s). 2018 Open Access This article is distributed under the terms of the Creative Commons Attribution 4.0 International License (http://creativecommons.org/licenses/by/4.0/), which permits unrestricted use, distribution, and reproduction in any medium, provided you give appropriate credit to the original author(s) and the source, provide a link to the Creative Commons license, and indicate if changes were made. The Creative Commons Public Domain Dedication waiver (http://creativecommons.org/publicdomain/zero/1.0/) applies to the data made available in this article, unless otherwise stated. immunoglobulin [5-7]. Moreover, the rituximab, an anti-CD20 immunobiological drug, has been administered in refractory SAM cases $[7,8]$.

Mycophenolate mofetil (MMF) is an agent that inhibits the mitosis and proliferation of $\mathrm{T}$ and $\mathrm{B}$ lymphocytes and has been successfully used to treat different autoimmune systemic diseases [9]. However, only a few studies in the literature have investigated the use of MMF in adult patients with SAM [10-20]. Furthermore, as limitations, the majority of these studies are case reports or case series $[10,12,13,15-18,20]$ and analyzed only SAM patients with pulmonary disease activity $[15,19,20]$. Those who used rituximab $[10-17,19,20]$ or anti-synthetase syndrome (ASS) patients [10-20] have not been studied.

The aim of the present case series was to evaluate the safety and efficacy of MMF (monotherapy or coadjuvant drug) in refractory SAM (DM, PM, ASS or clinically 
amyopathic DM) as monotherapy or in combination of immunosuppressants.

\section{Methods}

This retrospective, case series included 21 consecutive adult patients with refractory SAM: classical DM or PM, according to Bohan and Peter's criteria [21, 22], clinically amyopathic DM, according to Gerami et al. [23], and ASS which was defined as myositis, arthritis, pulmonary disease, positive anti-synthetase antibody, with or without mechanic's hands, fever and/or Raynaud's phenomenon [24].

Refractoriness was defined as primarily cutaneous (worsing heliotrope rash and/or Gottron's sign, new cutaneous lesions attributed to MAS), muscular (objective and progressive limb weakness), articular (arthritis) and/or pulmonary activity (progressive dyspnea), hampering glucocorticoid tapering and/or inadequate response to at least two immunosuppressive or immunomodulatory drugs at full-dose for a minimum period of three months, given sequentially or concomitantly [25].

To improve the homogeneity of the sample under study, only patients followed up at our outpatient clinic between 2010 and 2016 were included.

MMF treatment was defined as effective when the drug promoted over 50\% improvement in the initial: $\mathrm{cu}-$ taneous (evaluated clinically by the rheumatologists from Outgoing clinic); muscular (clinical muscle strength graded according to the Medical Research Council [26]) and/or laboratory parameters (serum creatine phosphokinase level - reference range: 24 - $173 \mathrm{IU} / \mathrm{L}$ - assayed by automated kinetic methods)]; articular (arthritis) or pulmonary (subjective dyspnea associated simultaneously with confirmed "ground-glass" on high-resolution chest computed tomography) activity. Comparisons of creatine phosphokinase level values at initial and after 6 months of MMF were considered as expected when variations ranged up to $20 \%$. Moreover, glucocorticoid tapering of over $50 \%$ of initial dose was also considered evidence of efficacy of MMF.

All patients were followed for 6 consecutive months after MMF introduction and were examined at baseline and after 6 months by the same examiner.

Myositis overlap syndromes, neoplasia associated myositis, necrotizing myopathies, muscular dystrophy, inclusion body myositis, metabolic myopathies, irregular or doubt treatment adhesions were excluded.

Data were obtained from the ongoing electronic database protocol applied all patients with SAM at $1-6$ month intervals entailing extensive clinical and laboratory evaluations, including the assessment relevant to this study.

Statistical analysis. The Kolmogorov-Smirnov test was used to evaluate the distribution of each parameter. The demographic and clinical features are expressed as the means \pm standard deviations for the continuous variables or as frequencies and percentages for the categorical variables. The medians $\left(25^{\text {th }}-75^{\text {th }}\right.$ percentiles) were calculated for the continuous variables that were not normally distributed. Comparisons between the patients at initial and after 6 months of MMF were performed using Student's $t$-test or Wilcoxon test for continuous variables, and $P<0.05$ was considered significant. All of the analyses were performed with the SPSS 15.0 statistics software (Chicago, USA).

\section{Results}

Twenty consecutive patients with refractory SAM treated with MMF were initially analyzed. In 7 patients, previous immunosuppressive drugs were exchanged for MMF (monotherapy), whereas in 13, MMF was associated with previous immunosuppressant (Table 1).

Patients \#11 used rituximab 12 months before switch to MMF.

As an internal service protocol, the patients were not using antimalarials, except for one patient (\#5).

In 17 out of 20 refractory MAS patients (11 DM, three PM, two ASS, one clinically amyopathic DM) (Table 1), MMF was introduced with good tolerance and with $100 \%$ of adhesion. The median dose of MMF was $2 \mathrm{~g} /$ day. This group comprised patients that were predominantly women, with a mean age of $46.2 \pm 12.6$ years and median disease duration of 2.0 years. All 17 patients used glucocorticoids (methylprednisolone or prednisone) and received previously a median of three immunosuppressive drugs (Table 1).

Of this group, 8 had muscle activity, three muscular and skin activities, three cutaneous activities, two pulmonary activities, one cutaneous and pulmonary activity and one had muscular, cutaneous and pulmonary activity. No cases had articular activity.

During the 6-month follow-up, prednisone median dose was significant tapering from 15.0 to $5.0 \mathrm{mg} /$ day $(P=0.005)$. Moreover, the prednisone tapering was achieved in 14 out of 17 patients. However, glucocorticoid tapering of more than half occurred in 11 patients, all of whom had good clinical activity response using MMF.

As an additional analysis, the MAS patients with MMF as monotherapy $(n=6)$ were compare to those with MMF in combination therapy $(n=11)$. All clinical, laboratory, therapeutic and outcome parameters were comparable between both groups $(P>0.05)$.

In three out of 20 refractory female patients (one DM, one PM and one ASS) with cutaneous, articular and/or muscular activity, MMF was suspended in less than two month, because of gastrointestinal intolerance. The maximum dose of MMF in these patients was $1.5 \mathrm{~g} /$ day.

There were no cases of death or infection during the follow-up of the patients analyzed. 
Table 1 General features of 17 refractory idiopathic systemic autoimmune myopathies

\begin{tabular}{|c|c|c|c|c|c|c|c|c|c|c|c|}
\hline \multirow[t]{2}{*}{ No } & \multirow[t]{2}{*}{ Disease } & \multirow{2}{*}{$\begin{array}{l}\text { Disease } \\
\text { (years) }\end{array}$} & \multicolumn{3}{|l|}{ Treatment } & \multicolumn{2}{|l|}{ Activity } & \multicolumn{2}{|c|}{ CPK (U/L) } & \multicolumn{2}{|c|}{ Prednisone $\left(\mathrm{mg} /\right.$ day) ${ }^{*}$} \\
\hline & & & Previous & $\begin{array}{l}\text { Immediately } \\
\text { Before MMF }\end{array}$ & Current & Initial & $\begin{array}{l}6 \text { months after } \\
\text { MMF treatment }\end{array}$ & Initial & $\begin{array}{l}6 \text { months after } \\
\text { MMF treatment }\end{array}$ & Inicial & $\begin{array}{l}6 \text { months after } \\
\text { MMF treatment }\end{array}$ \\
\hline 1 & PM & 2 & MP,Pred,Aza,CYC & $\mathrm{CP}$ & $\mathrm{CP}, \mathrm{MMF}$ & $P$ & $P$ & 95 & 130 & 5.0 & 20.0 \\
\hline 2 & DM & 2 & Pred,Aza,MTX,CYC & AZA & MMF & P & Remission & 48 & 66 & 15.0 & 5.0 \\
\hline 3 & ASS & 1 & MP,Pred,IVIg,Aza,MTX,CYC & CYC & MMF & $\mathrm{Mu}, \mathrm{C}, \mathrm{P}$ & $\mathrm{Mu}$ & 242 & 139 & 20.0 & 10.0 \\
\hline 4 & ASS & 2 & Pred,Aza,MTX,CYC & MTX & MTX, MMF & $\mathrm{Mu}, \mathrm{C}$ & Remission & 167 & 200 & 10.0 & 5.0 \\
\hline 5 & $\mathrm{DM}$ & 8 & Pred,AM,Aza,CP,RTX,Tac & $\mathrm{AM}, \mathrm{Tac}$ & AM, Tac, MMF & $\mathrm{Mu}, \mathrm{C}$ & c & 141 & 53 & 15.0 & 20.0 \\
\hline 6 & $\mathrm{DM}$ & 3 & Pred,Aza,MTX & AZA & AZA, MMF & $\mathrm{Mu}, \mathrm{C}$ & $\mathrm{Mu}$ & 268 & 148 & 15.0 & 7.5 \\
\hline 7 & $\mathrm{DM}$ & 2 & MP,Pred,Aza,MTX & MTX & MMF & $\mathrm{Mu}$ & $\mathrm{Mu}$ & 40 & 20 & 50.0 & 30.0 \\
\hline 8 & $\mathrm{DM}$ & 6 & MP,Pred,Aza,MTX,CP & $\mathrm{MTX}, \mathrm{CP}$ & $\mathrm{CP}, \mathrm{MMF}$ & $\mathrm{Mu}$ & $\mathrm{Mu}$ & 249 & 2120 & 10.0 & 15.0 \\
\hline 9 & PM & 6 & MP,Pred,Aza,MTX & AZA & $A Z A, M M F$ & $\mathrm{Mu}$ & $\mathrm{Mu}$ & 1534 & 3517 & 5.0 & 0 \\
\hline 10 & $\mathrm{DM}$ & 1 & MP,Pred,Aza,CYC,RTX & RTX & RTX, MMF & $\mathrm{Mu}$ & $\mathrm{Mu}$ & 215 & 255 & 15.0 & 2.5 \\
\hline 11 & PM & 1 & Pred,Aza,MTX & - & MMF & $\mathrm{Mu}$ & $\mathrm{Mu}$ & 118 & 205 & 60.0 & 5.0 \\
\hline 12 & $\mathrm{DM}$ & 1 & MP,AM,AZA,MTX & AZA & MMF & $\mathrm{Mu}$ & $\mathrm{Mu}$ & 35 & 30 & 40.0 & 5.0 \\
\hline 13 & $\mathrm{DM}$ & 1 & MP,Pred,AZA,MTX & MTX & MTX, MMF & $\mathrm{Mu}$ & Remission & 245 & 257 & 10.0 & 0 \\
\hline 14 & $\mathrm{DM}$ & 5 & $M P, A M, A Z A, M T X, C P$ & $\mathrm{AZA}, \mathrm{CP}$ & AZA, MMF & $\mathrm{Mu}$ & $\mathrm{Mu}$ & 858 & 268 & 10.0 & 0 \\
\hline 15 & $\mathrm{DM}$ & 1 & Pred,AZA,CYC & - & MMF & $C, P$ & C & 114 & 138 & 15.0 & 5.0 \\
\hline 16 & $\mathrm{DM}$ & 1 & MP,Pred,MTX & MTX & MTX, MMF & C & Remission & 100 & 80 & 12.5 & 5.0 \\
\hline \multirow[t]{2}{*}{17} & CADM & 3 & Pred,AZA,MTX,LFN,CYC & AZA,LFN & AZA, MMF & C & c & 79 & 95 & 60.0 & 2.5 \\
\hline & & $\begin{array}{l}2.0 \\
(1.0-4.0)\end{array}$ & & & & & & & & $\begin{array}{l}15.0 \\
(10.0-30.0)\end{array}$ & $\begin{array}{l}5.0 \\
(2.5-12.5)\end{array}$ \\
\hline
\end{tabular}

$A M$ antimalarials, $A S S$ anti-synthetase syndrome, $A Z A$ azathioprine, $C P K$ creatine phosphokinase, $C P$ cyclosporine, $C$ cutaneous, $C A D M$ clinically amyopathic dermatomyositis, CYC cyclophosphamide, DM dermatomyositis, $F$ female, $I V I g$ intravenous human immunoglobulin, $L F N$ leflunomide, $M$ male,

$M P$ methylprednisolone pulse therapy, MTX methotrexate, Mu muscular, PM polymyositis, $P$ pulmonary, Pred prednisone, RTX rituximab, Tac tacrolymus

Pred: current vs. 6 months: $P=0.005$

\section{Discussion}

This case series showed that MMF, as a monotherapy or coadjunt drug, is relatively safe and effective in patients with refractory SAM.

A strict exclusion in rare diseases criteria was employed in this study, however a sample of 20 consecutive patients with refractory SAM was analyzed based on previously standardized and parameterized data. The protocol was performed at the same service adopting the same standardization of reports, thereby reducing inter-examiner variability. Only patients with refractoriness were included.

MMF has been used in several systemic autoimmune diseases, such as systemic sclerosis, rheumatoid arthritis, Sjögre's syndrome, systemic lupus erythematosus [16, 27-29]. However, there are few studies in the literature investigating the use of MMF in adult patients with SAM [10-20].

Most studies are case reports or case series and MMF was found to promote significant clinical and laboratory improvement in patients with SAM [10, 12-16, 19, 20].

According to the study by Majithia and Harisdangkul [10], 6 out of 7 refractory SAM had marked improvement, with good tolerance, in active myositis using MMF. This response rate was higher than ours, however in a group with less severity and in previous use of a smaller number of immunosuppressive drugs.

In another study [13], MMF was effective for controlling cutaneous activity in all four patients with SAM analyzed, also resulting in glucocorticoid tapering. In 10 out of 12 patients with recalcitrant DM, Edge et al. [14] observed an improvement in muscular and cutaneous activity after four weeks of treatment with MMF.

Probably we found a smaller rate of success because of all patients of our sample had refractory and severe disease.

The heterogeneity of response evaluation in myopathies in the literature is present. Better criteria have been established [30-33], but in relation to DM, for example, there is still a difficulty in assessing improvement, especially in those with little muscle involvement. The response assessment parameter of the present study was based mainly on the clinical criteria.

Previous study showed that antimalarial could predispose patients with DM/PM to developing herpes zoster, particularly women and DM patients [29]. Therefore, as an internal service protocol, our patients were not using antimalarials (except for one patient) at the time of this study.

Facing the previous refractoriness, in two thirds of the patients, the MMF was introduced as a coadjuvant in the 
present study. However, during follow-up, there was no difference between this group and those who used MMF as monotherapy for the response parameters analyzed.

In the present study, most frequent side effects of MMF were associated with the gastrointestinal tract (nausea, vomiting, abdominal pain and/or diarrhea). Intolerance was observed in three out of the 20 patients in the present analysis, comparable to findings of other studies [12-14].

Akin to the present study, some investigations have also shown that MMF is safe in patients with SAM $[10,14,16]$. There were no cases of infection or death events in our sample. By contrast, Rowin et al. [11] reported that three out of their $10 \mathrm{DM}$ patients developed opportunistic infections with MMF (pulmonary infections: Blastomycosis, Mycobacterium xenopi, legionella).

Limitations of this study include the short follow-up of 6 months. In addition, possible inclusion of more severe cases of the disease due to the characteristics of our tertiary care centre should also be considered. Finally, as this is a review of retrospective cases, tools such as Manual Muscle Testing (MMT)-8 [31], 2016 European League Against Rheumatism / American College of Rheumatology (EULAR/ACR) response criteria [34] were not used and pulmonary involvement was not analyzed with pulmonary function test (at baseline and 6 months of MMF) and high-resolution chest computed tomography (6 months of MMF).

\section{Conclusions}

MMF was relatively well-tolerated, safe and effective in patients with refractory SAM, at least in the short follow-up of 6 consecutive months. Further studies are needed to confirm the data found in the present study.

\section{Abbreviations \\ AM: Antimalarials; ASS: Anti-synthetase syndrome; AZA: Azathioprine; C: Cutaneous; CADM: Clinically amyopathic dermatomyositis; CP: Cyclosporine; CPK: Creatine phosphokinase; CYC: Cyclophosphamide; DM: Dermatomyositis; EULAR/ACR: European League Against Rheumatism / American College of Rheumatology; F: Female; IVlg: Intravenous human immunoglobulin; LFN: Leflunomide; M: Male; MMF: Mycophenolate mofetil; MMT: Manual Muscle Testing; MP: Methylprednisolone pulse therapy; Mu: Muscular; P: Pulmonary; PM: Polymyositis; Pred: Prednisone; RTX: Rituximab; SAM: Systemic autoimmune myopathies; Tac: Tacrolymus}

\section{Availability of data and materials}

Please contact author for data requests.

\section{Authors' contributions}

All authors contributed equally to write and review the manuscript. All authors read and approved the final manuscript

\section{Ethics approval and consent to participate}

This study was approved by the local Ethics Committee (HCFMUSP, CAPPesq, Number 0039/10) and all participant signed the informed consent form.
Competing interests

All authors declare that they have no competing interest.

\section{Publisher's Note}

Springer Nature remains neutral with regard to jurisdictional claims in published maps and institutional affiliations.

Received: 20 March 2018 Accepted: 7 October 2018

Published online: 22 October 2018

\section{References}

1. Dalakas MC. Inflammatory muscle diseases. N Engl J Med. 2015;372:1734-47.

2. Dalakas MC. Pathogenesis and therapies of immune-mediated myopathies. Autoimmun Rev. 2012;11:203-6.

3. Nava A, Orozco-barocio G. Approach to the differential diagnosis of inflammatory myopathies. Rheumatol Clin. 2009;5:32-4.

4. Irazoque-Palazuelos F, Barragán-Navarro Y. Inflammatory myopathies: epidemiology, etiology and classification. Rheumatol Clin. 2009;5:2-5.

5. Aggarwal R, Oddis CV. Therapeutic advances in myositis. Curr Opin Rheumatol. 2012;24:635-41.

6. Distad BJ, Amato AA, Weiss MD. Inflammatory myopathies. Curr Treat Options Neurol. 2011;13:19-30.

7. Ernste FC, Reed AM. Idiopathic inflammatory myopathies: current trends in pathogenesis, clinical features, and up-to-date treatment recommendations. Mayo Clin Proc. 2013;88:83-105.

8. Ytterberg SR. Treatment of refractory polymyositis and dermatomyositis. Curr Rheumatol Rep. 2006:8:167-73.

9. Bandelier C, Guerne PA, Genevay S, Finckh A, Gabay C. Clinical experience with mycophenolate mofetil in systemic autoimmune conditions refractory to common immunosuppressant therapies. Swiss Med Wkly. 2009;139:41-6.

10. Majithia V, Harisdangkul V. Mycophenolate mofetil (CellCept): an alternative therapy for autoimmune inflammatory myopathy. Rheumatology. 2005;44: 386-9.

11. Rowin J, Amato AA, Deisher N, Cursio J, Meriggioli MN. Mycophenolate mofetil in dermatomyositis: is it safe? Neurology. 2006;66:1245-7.

12. Tausche AK, Meurer M. Mycophenolate mofetil for dermatomyositis. Dermatology. 2001;202:341-3.

13. Gelber AC, Nousari HC, Wigley FM. Mycophenolate mofetil in the treatment of severe skin manifestations of dermatomyositis: a series of 4 cases. J Rheumatol. 2000;27:1542-5.

14. Edge JC, Outland JD, Dempsey JR, Callen JP. Mycophenolate mofetil as an effective corticosteroid-sparing therapy for recalcitrant dermatomyositis. Arch Dermatol. 2006:142:65-9.

15. Morganroth PA, Kreider ME, Werth VP. Mycophenolate mofetil for interstitial lung disease in dermatomyositis. Arthritis Care Res. 2010;62:1496-501.

16. Saketkoo LA, Espinoza LR. Experience of mycophenolate mofetil in 10 patients with autoimmune-related interstitial lung disease demonstrates promising effects. Am j Med Sci. 2009;337:329-35.

17. Danieli MG, Calcabrini L, Calabrese V, Marchetti A, Loqullo F, Gabrielli A. Intravenous immunoglobulin as add on treatment with mycophenolate mofetil in severe myositis. Autoimmun Rev. 2009;9:124-9.

18. Parziale N, Kovacs SC, Thomas CB, Srinivasan J. Rituximab and mycophenolate combination therapy in refractory dermatomyositis with multiple autoimmune disorders. J Clin Neuromuscul Dis. 2011:13:63-7.

19. Mira-Avendano IC, Parambil JG, Yadav R, Arrossi V, Xu M, Chapman JT, et al. A retrospective review of clinical features and treatment outcomes in steroid-resistant interstitial lung disease from polymyositis / dermatomyositis. Respir Med. 2013:107:890-6.

20. Tsuchiya H, Tsuno H, Inoue M, Takahashi Y, Yamashita H, Kaneko H, et al. Mycophenolate mofetil therapy for rapidly progressive interstitial lung disease in a patient with clinically amyopathic dermatomyositis. Mod Rheumatol. 2014;24:694-6.

21. Bohan A, Peter JB. Polymyositis and dermatomyositis (first of two parts). N Engl J Med. 1975;292:344-7.

22. Bohan A, Peter JB. Polymyositis and dermatomyositis (second of two parts). N Engl J Med. 1975;292:403-7.

23. Gerami P, Schope JM, McDonald L, Alling HW, Sontheimer RD. A systematic review of adult-onset clinically amyopathic dermatomyositis (dermatomyositis sine myositis): a missing link within the spectrum of the idiopathic inflammatory myopathies. J Am Acad Dermatol. 2006;54:597-613. 
24. Mahler M, Miller FW, Fritzler MJ. Idiopathic inflammatory myopathies and the anti-synthetase syndrome: a comprehensive review. Autoimmun Rev. 2014;13:367-71.

25. Brandão M, Marinho A. Idiopathic inflammatory myopathies: Definition and management of refractory disease. Autoimmun Rev. 2011;10:720-4.

26. Medical Research Council: Aids to the investigation of peripheral nerve injuries. War Memorandun. No 7, 2. Ed. London: Her Majesty's Stationery Office, 1943.

27. Appel GB, Gerald B, Radhakrishnan J, Ginzler EM. Use of mycophenolate mofetil in autoimmune and renal diseases. Transplantation. 2005;80:S265-71.

28. laccarino L, Rampudda M, Canova M, Libera SD, Sarzi-Puttinic P, Doria A. Mycophenolate mofetil: what is its place in the treatment of autoimmune rheumatic diseases? Autoimmun Rev. 2007;6:190-5.

29. Cunha GF, Souza FH, Levy-Neto M, Shinjo SK. Chloroquine diphosphate: a risk factor for herpes zoster in patients with dermatomyositis / polymyositis. Clinics. 2013;68:621-7.

30. Bruce B, Fries JF. The Stanford Health Assessment Questionnaire: dimensions and practical applications. Health Qual Life Outcomes. 2003;1:20.

31. Rider LG, Koziol D, Giannini EH, Jain MS, Smith MR, Whitney-Mahoney K, et al. Validation of manual muscle testing and a subset of eight muscles for adult and juvenile idiopathic inflammatory myopathies. Arthritis Care Research (Hoboken). 2010;62:465-72.

32. Rider LG, Feldman BM, Perez MD, Rennebohm RM, Lindsley CB, Zemel LS, et al. Development of validated disease activity and damage indices for the juvenile idiopathic inflammatory myopathies: I. Physician, parent, and patient global assessments. Juvenile Dermatomyositis Disease Activity Collaborative Study Group. Arthritis Rheum. 1997;40:1976-83.

33. Sultan SM, Allen E, Oddis CV, Kiely P, Cooper RG, Lundberg IE, et al. Reliability and validity of the myositis disease activity assessment tool. Arthritis Rheum. 2008;58:3593-9.

34. Rider LG, Ruperto N, Pistorio A, Erman B, Bayat N, Lachenbruch PA, et al. International Myositis Assessment and Clinical Studies Group and the Paediatric Rheumatology International Trials Organisation. 2016 ACR-EULAR adult dermatomyositis and polymyositis and juvenile dermatomyositis response criteria-methodological aspects. Rheumatology (Oxford). 2017;56:1884-93.

Ready to submit your research? Choose BMC and benefit from:

- fast, convenient online submission

- thorough peer review by experienced researchers in your field

- rapid publication on acceptance

- support for research data, including large and complex data types

- gold Open Access which fosters wider collaboration and increased citations

- maximum visibility for your research: over $100 \mathrm{M}$ website views per year

At $\mathrm{BMC}$, research is always in progress.

Learn more biomedcentral.com/submissions 